\title{
Parvovirus B19 as a Possible Cause of Skin Rash after Allogeneic Transplantation?
}

\author{
Shigeo Fuji \\ Department of Hematology, Osaka International Cancer Institute, Osaka, Japan
}

Viral infections are still the cause of morbidity and mortality after allogeneic hematopoietic cell transplantation (HCT). However, the occurrence of viral infection is not necessarily associated with an adverse impact on the post-transplant outcome [1]. Viral infection could drive the reconstitution of virus-specific immunity including $\mathrm{T}$ cells after allogeneic HCT, which could lead to a possible beneficial effect associated with reactivity against the virus as well as alloreactivity against leukemic cells. Such virus-specific immunity also could lead to a possible detrimental effect associated with alloreactivity against normal tissues. Previous studies focusing on cytomegalovirus (CMV) infections after allogeneic HCT found the reduced incidence of relapse after allogeneic HCT when the reactivation of CMV occurred after allogeneic HCT, although the significance of beneficial impact differed among studies $[2,3]$.

In this issue of Acta Haematologica, Weber et al. [4] found that the presence of Parvovirus B19 but not Herpesvirus genome in acute skin rash after allogeneic HCT correlated with the clinical outcome. At first, it is intriguing that Parvovirus B19 was detected in the skin tissue after allogeneic HCT, although the findings have to be re-confirmed in independent studies and also by the different techniques such as immunohistochemistry in the future.

Furthermore, it is also intriguing that the clinical outcome in patients with Parvovirus B19 was significantly better than that in those without Parvovirus B19. In con- trast to various herpesvirus infections such as CMV, the study focusing on Parvovirus B19 was limited in the field of allogeneic HCT. Infection with parvovirus B19 has various clinical manifestations including erythema, arthritis and vasculitis, and severe anemia. The virus has a high affinity for human bone marrow and replicates in erythroid progenitor cells, and it is well-known that Parvovirus B19 infection was associated with pure red cell aplasia after allogeneic HCT [5]. However, data about Parvovirus B19 infection as a cause of erythema after allogeneic HCT was scarce, possibly due to a difficulty to test the presence of Parvovirus B19 in the small sample of skin biopsy. Following the findings of current study by Weber et al. [4], further studies are warranted to elucidate the impact of Parvovirus B19 infection as a form of erythema after allogeneic HCT. Possibly, the appropriate management of patients with erythema associated with Parvovirus B19 is different from that without Parvovirus B19: intravenous immunoglobulin might be a treatment option, and we do not need systemic corticosteroids in such cases. Collectively, the clinical relevance of Parvovirus $\mathrm{B} 19$ in the skin tissue after allogeneic HCT should be determined in the future.

\section{Conflict of Interest Statement}

The author has no conflicts of interest to declare. karger@karger.com

www.karger.com/aha

Karger! (c) 2020 S. Karger AG, Base 


\section{References}

Parvovirus B19 and Skin Rash after alloHCT
1 Fuji S, Kapp M, Einsele H. Alloreactivity of virus-specific $\mathrm{T}$ cells: possible implication of graft-versus-host disease and graft-versus-leukemia effects. Front Immunol. 2013 Oct;4:330.

2 Elmaagacli AH, Steckel NK, Koldehoff M, Hegerfeldt Y, Trenschel R, Ditschkowski M, et al. Early human cytomegalovirus replication after transplantation is associated with a decreased relapse risk: evidence for a putative virus-versus-leukemia effect in acute myeloid leukemia patients. Blood. 2011 Aug;118(5): 1402-12.

3 Green ML, Leisenring WM, Xie H, Walter RB, Mielcarek M, Sandmaier BM, et al. CMV re- activation after allogeneic HCT and relapse risk: evidence for early protection in acute myeloid leukemia. Blood. 2013 Aug;122(7): 1316-24.

4 Weber T, Schmidberger A, Ligeti K, Bauer M, Rosenwald A, Müller L. Presence of Parvovirus B19 but not Herpesvirus genome in acute skin rash after allogeneic stem cell transplantation correlates with outcome. Acta Haematol. DOI: 10.1159/509739.

5 Eid AJ, Brown RA, Patel R, Razonable RR. Parvovirus B19 infection after transplantation: a review of 98 cases. Clin Infect Dis. 2006 Jul;43(1):40-8. 